\title{
Fatores de risco para hipertensão arterial e níveis pressóricos em estudantes de enfermagem.
}

\author{
Gabriella P. Previato Piton (IC), José Luiz Tatagiba Lamas (PQ).
}

\section{Resumo}

Os objetivos desta pesquisa foram determinar os níveis de pressão arterial e identificar fatores de risco para hipertensão em estudantes de Enfermagem e avaliar a relação destes com o cumprimento de atividades acadêmicas. Trata-se de um estudo transversal, descritivo, não experimental, desenvolvido junto a estudantes de ambos os sexos e acima de 18 anos da graduação de uma universidade pública, que responderam a um questionário sobre a exposição a fatores de risco para hipertensão, informações sócio demográficas e as atividades diárias da graduação, sendo avaliadas associações entre os valores pressóricos e a exposição a fatores de risco. Foi observada a presença de fatores de risco para hipertensão e aumento dos níveis de pressão na presença dos mesmos na amostra abordada. Conclui-se que estes estudantes estão sujeitos a fatores de risco para hipertensão arterial. Palavras Chave: Hipertensão Arterial, Qualidade de Vida, Fatores de Risco.

\section{Introdução}

A hipertensão arterial (HA) é caracterizada como um problema mundial de saúde pública, com um impacto social incontestável, pois além de ser a doença vascular de maior prevalência no mundo é um fator de risco para doenças cerebrovasculares, importante causa de óbito no Brasil. 10 ingresso dos estudantes na universidade diminui o tempo do aluno para a prática de esportes e exercício físico, acentuando o sedentarismo. Além disso, também aumentam a responsabilidade, o tempo de estudo e as cobranças. $O$ tempo de sono, lazer e interação social diminuem, trazendo novos componentes na vida do graduando que podem lhe causar estresse e angústia. Estes fatores podem influenciar na exposição dos estudantes aos fatores de risco para o desenvolvimento de HA. É importante salientar que os fatores de risco para um adulto jovem se originam na comunidade em que ele está inserido, nos padrões de vida e na sua história familiar.2 Os objetivos desta pesquisa são determinar os níveis de pressão arterial de estudantes de Enfermagem, identificar fatores de risco para hipertensão arterial presentes nesse grupo e avaliar a relação entre níveis de pressão arterial e o cumprimento de atividades acadêmicas por estudantes de enfermagem.

\section{Resultados e Discussão}

Foram obtidos 50 sujeitos (47 mulheres), 26 ingressantes em 2013 e 24 de 2014, de um total de 73 alunos matriculados. A diferença no número de sujeitos do sexo feminino pode ser explicada devido à predominância do mesmo no curso. Em relação a exposição aos fatores de risco, $56 \%$ dos sujeitos apresentaram histórico familiar de hipertensão arterial, $70 \%$ dos sujeitos não realizam atividade física, 50\% fazem uso de anticoncepcionais. Em relação a níveis de estresse, raiva, irritação e ansiedade, $70 \%$ dos sujeitos consideram-se estressados, $56 \%$ consideraram que sentem raiva e $40 \%$ consideram-se irritados quando expostos a um problema ou dificuldade e $74 \%$ consideram-se ansiosos. Em relação a qualidade do sono, $62 \%$ consideram a qualidade do seu sono ruim ou muito ruim. As respostas mais frequentes citadas pelos participantes ao questionário sobre as fontes de estresse, raiva, irritação e ansiedade foram: carga horária da faculdade, trânsito e problemas com transporte, falta de dinheiro, relações familiares, tarefas domésticas, conciliar vida acadêmica e vida pessoal, falta de exercício físico, professores da universidade, estágios, falta de dinheiro e namoro. Avaliou-se a comparação da Pressão Arterial Sistólica Média (PASM) e Pressão Arterial Diastólica Média (PADM) em função das variáveis dicotômicas através do teste $t$ de Student para amostras independentes, quando os dados seguiam a distribuição normal, e o teste de MannWhitney, quando os dados seguiam a distribuição não normal. Para as variáveis qualitativas com mais de duas categorias, não foi possível aplicar teste estatístico, devido à baixa frequência de algumas categorias. As comparações que apresentaram resultados significativos foram o valor de PASM em relação à ingestão de café, o valor de PADM em relação aos níveis de estresse e o valor de PASM em relação aos níveis de raiva. O programa estatístico utilizado foi o SPSS 20.0.

\section{Conclusões}

Os estudantes que compuseram a amostra estão expostos a fatores de risco para hipertensão arterialque já são capazes de alterar os valores de pressão arterial.

\section{Agradecimentos}

Ao SAE pela bolsa de Iniciação Científica concedida para a realização desta pesquisa.

\footnotetext{
Lessa I. Hipertensão arterial sistêmica no Brasil: tendência temporal. Caderno de Saúde Pública. Vol.26, n.8, pp. 1470-1470. 2010.

${ }^{2}$ Patsy R. Do Adulto Jovem ao Adulto de Meia-Idade. In: Perry AG, Potter PA. Hall A, Stockert PA. Fundamentos de Enfermagem. 7a Edição. Rio de Janeiro. Editora Mosby Elsevier. 2009. Cap. 13, p. $178-82$
} 